\title{
Outdoor second-hand cigarette smoke significantly affects air quality
}

To the Editor:

Second-hand smoke (SHS) may be significantly elevated outdoors and when adjacent to smoking areas [1,2]. This is of concern as SHS exposure is linked to adverse health outcomes, including respiratory disorders, cardiovascular diseases, and lung cancer [3-5]. Exposure to cancer-causing chemicals in outdoor areas is likely to occur in the presence of cigarette smoke [6], and worryingly, short periods of exposure to SHS are related to detectable levels of carcinogenic tobacco-specific nitrosamines in nonsmoking subjects [7].

A growing number of American cities have adopted policies that restrict tobacco smoking in outdoor locations such as parks. However, more lenient restrictions apply in Japan, where designated smoking areas have been created in streets where smoking is banned [6].

The contribution of SHS to environmental pollution in comparison with vehicular traffic has not yet been investigated. Pedestrian only streets, which are often narrow and lined by high buildings, particularly in European historic towns, are visited by large numbers of smokers. This architectural feature creates so-called "street canyons", characterised by limited natural air exchange where the presence of smokers may potentially generate large quantities of SHS.

In this study, to investigate the contribution of SHS to outdoor air quality, we compared the environmental pollution of a high-traffic area to that of a "street canyon" by measuring particulate matter (particles with a $50 \%$ cut-off aerodynamic diameter of $1 \mu \mathrm{m}$ (PM1), $2.5 \mu \mathrm{m}$ (PM2.5) and $10 \mu \mathrm{m}$ (PM10)) and vapour nicotine levels.

We hypothesised that the presence of smokers in restricted pedestrian areas may potentially generate large quantities of SHS, resulting in a deterioration of the outdoor air quality. A pedestrian-only area (Via Fiorichiari) in the city of Milan, Italy, with a high number of outdoor restaurants and bars, and the parallel high-traffic area of similar architectural design (Via Pontaccio) were set as location of the experiment. The two streets are about $60 \mathrm{~m}$ apart and connected at either end by two $7.5 \mathrm{~m}$ large streets. Both present a "street canyon" configuration as described earlier.

A gravimetrically pre-calibrated, laser-operated real-time portable aerosol analyser (Aerocet 531, MetOne Instruments, Grants Pass, OR, USA) was used to measure PM1, PM2.5 and PM10 levels. One instrument was installed $1.5 \mathrm{~m}$ from the ground on a balcony in the pedestrian area, while the other one was stationed in the adjacent high traffic street, with a vehicular traffic of 700-1000 vehicles per hour (counted directly).

Although no air pollution monitoring stations were available at a suitable distance, our PM analysers were gravimetrically calibrated to improve accuracy using the Beta Attenuation Monitor model BAM-102 of MetOne Instruments as a reference, with US Environmental Protection Agency (EPA) equivalence certificate number EQPM-0798-122 and TÜV-Report 936/21205333/A for PM10. Meorological conditions were very stable (absence of rain) with the temperature ranging from $22^{\circ} \mathrm{C}$ to $31^{\circ} \mathrm{C}$. Relative humidity ranged from $18 \%$ to $83 \%$ and wind speed from 0 to $7 \mathrm{~km} \cdot \mathrm{h}^{-1}$.

Outdoor nicotine vapour phase was measured by using passive samplers (Millipore Corp., Bedford, MA, USA), following the validated method of HAMmond [8] with a detection limit of $<0.02 \mu \mathrm{g} \cdot \mathrm{m}^{-3}$, the filters were then analysed using a gas chromatography method.

Cigarette consumption was estimated by assuming that each pedestrian walking into the area with a lit cigarette over a time span of an hour between $11.00 \mathrm{~h}$ and midnight represented one cigarette smoked. At the same time, the frequency of smokers seated at patios was evaluated using the mean of six consecutive counts performed every $10 \mathrm{~min}$.

Data were analysed using Graph Pad Prism 5.03 (GraphPad Software Inc., La Jolla, CA, USA). All results were expressed as mean \pm SEM. Comparisons between groups were made using two-way ANOVA. The cumulative effect of traffic and smoking on PM was expressed as the area under the curve (AUC). A p-value $<0.05$ was considered significant. Linear regression analysis was used to evaluate the relationships between the number of smokers and the environmental PM.

Even though PM1 concentration levels were similar in the two streets during the morning hours (figure 1a), in the evening between 18:00 $\mathrm{h}$ and midnight, $\mathrm{PM}_{1}$ was significantly elevated in the pedestrian area 
compared with the high traffic street $\left(2.1 \pm 0.03\right.$ versus $\left.1.00 \pm 0.03 \mu \mathrm{g} \cdot \mathrm{m}^{-3} ; \mathrm{p}<0.01\right)$ (figure $1 \mathrm{a}$ and $\left.\mathrm{d}\right)$. These findings were confirmed by a larger AUC for PM1 in the pedestrian area (AUC of 7.34 arbitrary units $(\mathrm{AU})$ ) compared with the high traffic street (1.07 AU) (figure 1d).

PM2.5 (figure $1 \mathrm{~b}$ and e) and PM10 (figure $1 \mathrm{c}$ and $\mathrm{f}$ ) were also more elevated in the evening in the pedestrian area compared with the high traffic street $\left(15.2 \pm 1.1\right.$ versus $67.2 \pm 8.9 \mu \mathrm{g} \cdot \mathrm{m}^{-3}$ and $13.00 \pm 1.1$ versus $59.70 \pm 5.5 \mu \mathrm{g} \cdot \mathrm{m}^{-3}$, respectively; both $\left.\mathrm{p}<0.05\right)$. The AUC confirmed the presence of higher levels of pollution in the pedestrian area both for PM2.5 (AUC of $69.33 \mathrm{AU}$ and $64.45 \mathrm{AU}$ for the pedestrian and traffic areas, respectively) (figure 1e) and PM10 (AUC of 291.8 AU and 271.1 AU, respectively) (figure 1f). Interestingly, after midnight, as the restaurants and bars closed, PM2.5 and PM10 were significantly elevated in the high traffic street compared with the pedestrian area (figure $1 \mathrm{~b}$ and c).

In summary, our data show that during evening hours air quality was worse in the pedestrian area compared with a high-traffic zone, and correlated with the number of cigarette smoked outdoors. Higher particulate matter levels in a pedestrian area were unexpected and are of concern.

An increment of $15 \mu \mathrm{g} \cdot \mathrm{m}^{-3}$ or more for PM2.5 levels, as measured in the pedestrian area in this study, is sufficient to generate a downgrade of one step in the air quality index, from "good" to "moderate" or from "moderate" to "unhealthy for sensitive groups", according to the US EPA standards [9]. Therefore, the magnitude of differences we observed is of medical interest.

The "street canyon" architecture of the streets we studied, which favours particulate matter stagnation due to reduced ventilation is likely to have contributed to our experimental findings; our results may not apply to streets with a different layout.

Because particulate matter levels were different in the two areas only during the evening hours, when a large number of smokers crowded into the pedestrian area, we assumed that cigarette smoke contributed to this finding; this hypothesis was reinforced by the strong correlation of particulate matter with the number of cigarettes smoked by the pedestrians $(\mathrm{r}=0.76, \mathrm{p}<0.05$ and $\mathrm{r}=0.8, \mathrm{p}<0.03$ for $\mathrm{PM} 1$ and $\mathrm{PM} 2.5$, respectively), and by the presence of vapour nicotine in the pedestrian $\left(0.07 \mu \mathrm{g} \cdot \mathrm{m}^{-3}\right)$ but not in the vehicular area. Furthermore, a causative negative effect of SHS on air quality is confirmed by the reversal
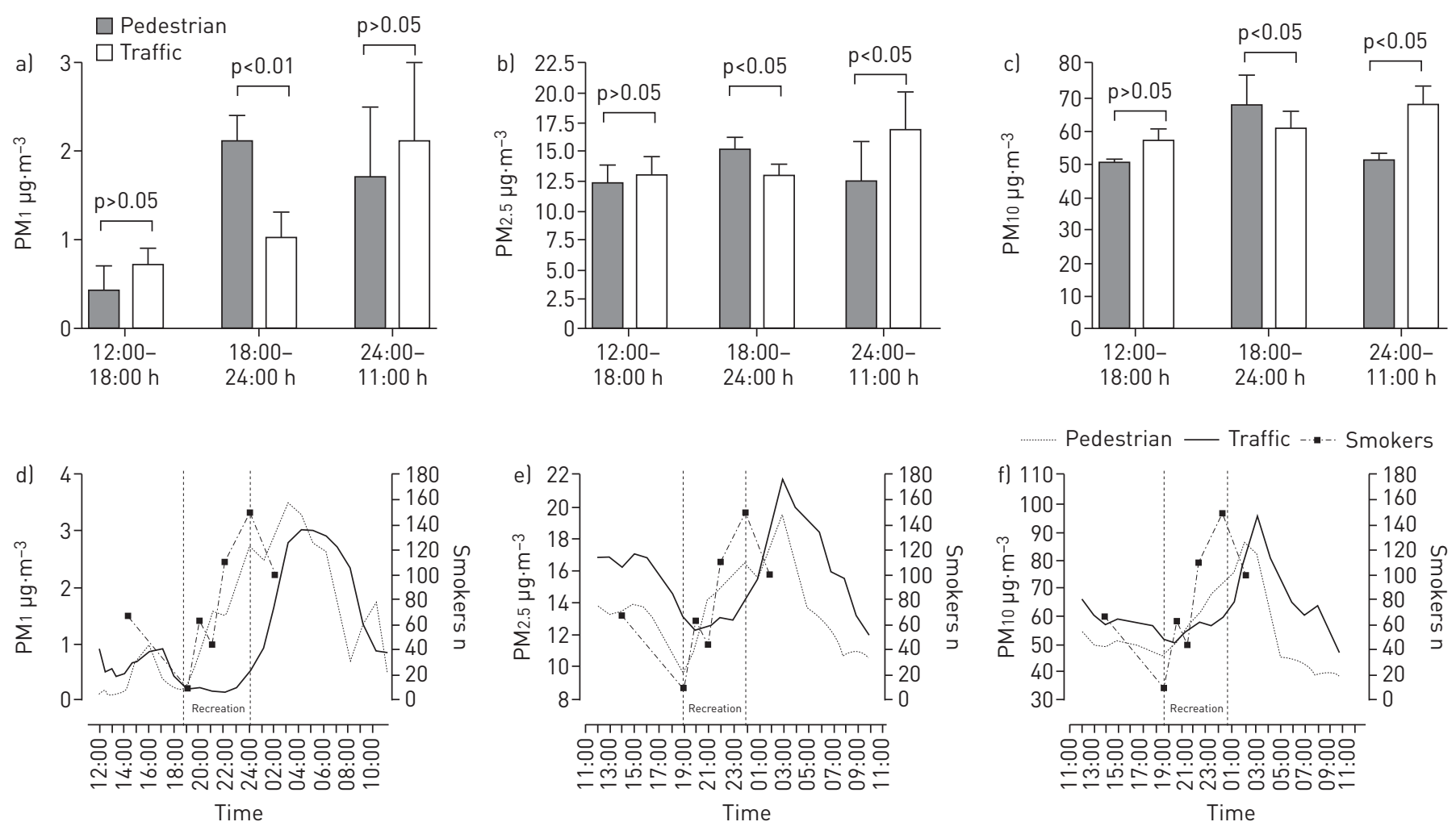

FIGURE 1 Comparison of particulate matter concentrations at different times of the day for particles with a $50 \%$ cut-off aerodynamic diameter of a) $1 \mu \mathrm{m}(\mathrm{PM} 1)$, b) $2.5 \mu \mathrm{m}$ ( $\mathrm{PM} 2.5$ ) and c) $10 \mu \mathrm{m}$ (PM10) and their corresponding time courses with the number of cigarettes smoked (d-f) in a pedestrian only area compared with a high vehicular traffic area. 
to poorer air quality in the high traffic road after midnight, when the restaurants and bars closed and there were no smokers the street.

In particular weather conditions outdoor SHS may rival indoor concentrations [10], creating an environment for the exposure to so-called smoking microplumes [11]. A $3 \mathrm{~h}$ exposure to outdoor SHS is sufficient to allow the uptake of some tobacco derived carcinogens like nitrosamines [7]; this may well occur in a pedestrian area.

The World Health Organization recommends a no smoking policy in outdoor settings wherever a SHS hazard is possible [12] and the scientific debate over a complete outdoor smoking ban is ongoing [13, 14]. In view of the public health implications of our results, implementing a smoking ban that includes outdoor SHS may be required to protect citizens from the dangers of SHS. zone http://ow.ly/DMW83007Xmo

\author{
Ario Alberto Ruprecht ${ }^{1,2,6}$, Cinzia De Marco ${ }^{1,6}$, Paolo Pozzi ${ }^{1,3}$, Roberto Mazza ${ }^{1}$, Elena Munarini ${ }^{1}$, Adriano Di Paco ${ }^{4}$, \\ Paolo Paredi ${ }^{5}$, Giovanni Invernizzi ${ }^{1,2, \uparrow}$ and Roberto Boffi ${ }^{1}$ \\ ${ }^{1}$ Tobacco Control Unit, Fondazione IRCCS Istituto Nazionale dei Tumori, Milan, Italy. ${ }^{2}$ Italian College GPs (SIMG), \\ Milan, Italy. ${ }^{3}$ Cardiopulmonary Rehabilitation Unit, Azienda Sociosanitaria Territoriale Lariana, Cantù, Italy. \\ ${ }^{4}$ Pulmonary Rehabilitation and Weaning Center, Auxilium Vitae, Volterra, Italy. ${ }^{5}$ Airway Disease Section, National \\ Heart and Lung Institute, Imperial College, London, UK. ${ }^{6}$ Both authors contributed equally.
}

Correspondence: Paolo Pozzi, Cardiopulmonary Rehabilitation Unit, Azienda Sociosanitaria Territoriale Lariana, Sant'Antonio Abate Hospital, Via Domea 4, 20063, Cantù, Italy. E-mail: paolo.pozzi@asst-lariana.it

Received: July 302015 | Accepted after revision: May 062016 | First published online: May 262016

Support statement: This work has been supported by the $5 \times 1000$ mille contribution; we wish to thank all those citizens who decided to donate their $5 \times 1000$ to IRCCS Fondazione Istituto Nazionale dei Tumori, Milan.

Conflict of interest: Disclosures can be found alongside this article at erj.ersjournals.com

Acknowledgements: We wish to dedicate this work to Giovanni Invernizzi who strongly contributed to this study before he passed away.

\title{
References
}

1 Sureda X, Martínez-Sánchez JM, López MJ, et al. Secondhand smoke levels in public building main entrances: outdoor and indoor PM2.5 assessment. Tob Control 2012; 21: 543-548.

2 Boffi R, Ruprecht A, Mazza R, et al. A day at the European Respiratory Society Congress: passive smoking influences both outdoor and indoor air quality. Eur Respir J 2006; 27: 862-863.

3 Loomis D, Grosse Y, Lauby-Secretan B, et al. The carcinogenicity of outdoor air pollution. Lancet Oncology 2013; 14: $1262-1263$.

4 Kostikas K, Minas M, Nikolaou E, et al. Secondhand smoke exposure induces acutely airway acidification and oxidative stress. Respir Med 2013; 107: 172-179.

5 Frazer K, Callinan JE, McHugh J, et al. Legislative smoking bans for reducing harms from secondhand smoke exposure, smoking prevalence and tobacco consumption. Cochrane Database Syst Rev 2016; 2: CD005992.

6 Cho $\mathrm{H}$, Lee K, Hwang $\mathrm{Y}$, et al. Outdoor tobacco smoke exposure at the perimeter of a tobacco-free university. $J$ Air Waste Manag Assoc 2014; 64: 863-866.

7 St Helen G, Bernert JT, Hall DB, et al. Exposure to secondhand smoke outside of a bar and a restaurant and tobacco exposure biomarkers in nonsmokers. Environ Health Perspect 2012; 120: 1010-1016.

8 Hammond SK. Evaluating exposure to environmental tobacco smoke. In: Winegar EDLH, eds. Sampling and Analysis of Airborne Pollutants. Florida, CRC Press, 1993; pp. 319-337.

9 Congressional Research Service. Air Quality: EPA's 2013 changes to particulate matter (PM) standard. http://fas.org:8080/sgp/crs/misc/R42934.pdf Date last updated: December 23, 2015.

10 Sureda X, Fernández E, López MJ, et al. Secondhand tobacco smoke exposure in open and semi-open settings: a systematic review. Environ Health Perspect 2013; 121: 766-773.

11 Acevedo-Bolton V, Ott WR, Cheng KC, et al. Controlled experiments measuring personal exposure to PM2.5 in close proximity to cigarette smoking. Indoor Air 2014; 24: 199-212.

12 World Health Organization. WHO Report on the Global Tobacco Epidemic, 2009: implementing smoke-free environments. Geneva, World Health Organization, 2009.

13 Potera C. Outdoor smoking areas: does the science support a ban? Environ Health Perspect 2013; 121: A229.

14 Hyland A, Barnoya J, Corral JE. Smoke-free air policies: past, present and future. Tob Control 2012; 21: 154-161. 